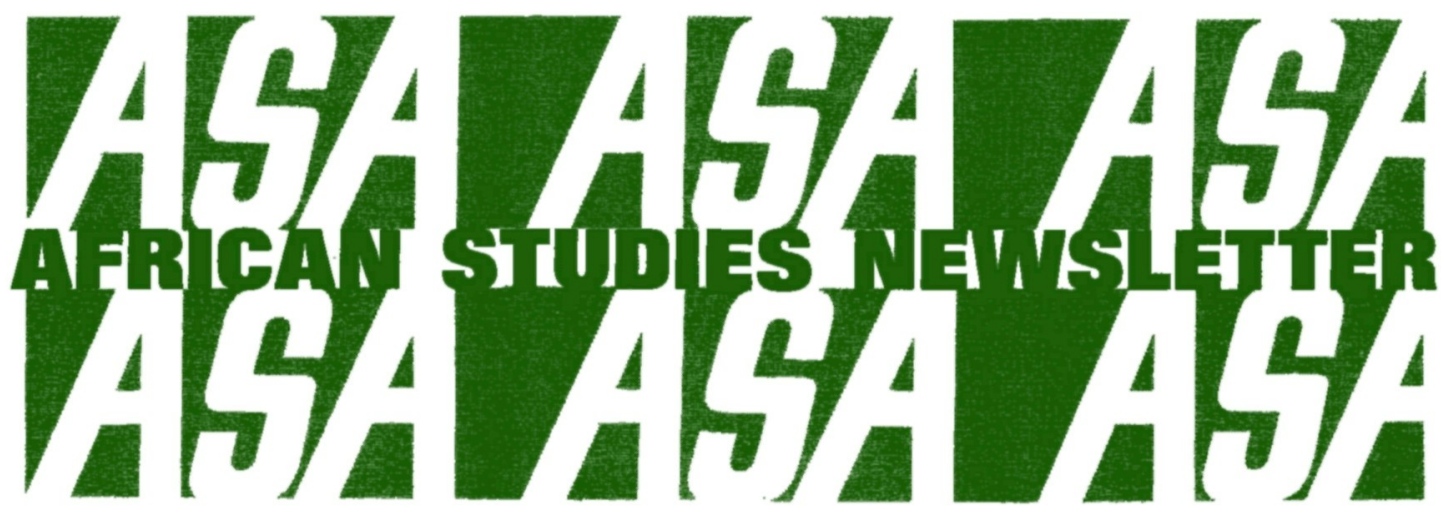

Volume IV

November-December 1971

Numbers 5-6

CONTENTS

Page

Annual Business Meeting......................... 2

Membership Report............................ 3

Meetings of the Board of Directors: November $3 \& 6 \ldots \ldots \ldots \ldots 4$

ASA Board and committee members : $1972 \ldots \ldots \ldots \ldots \ldots \ldots \ldots \ldots \ldots$

Minutes of committee meetings

Committee on Current Issues..................... 7

Research Liaison Committee..................... 9

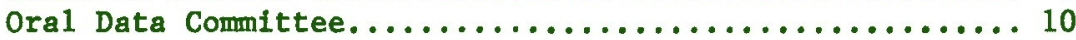

Literature Comittee......................... 11

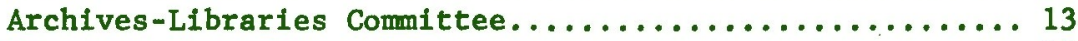

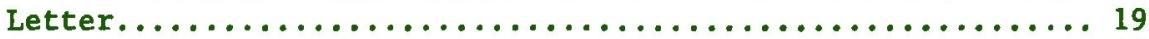

Deadlines for Fellowships and Grants................. 20

Specia1 Announcements............................ 21

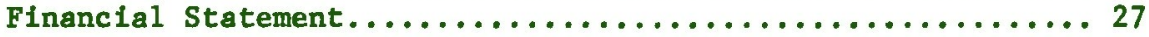

Report on the National Conference on Foreign Language and

Area Studies and World Affairs in Philadelphia.......... 28

International Education......................... 31

International Congress of Africanists................ 33

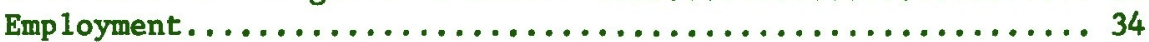

Meetings - Past and Future.......................... 36

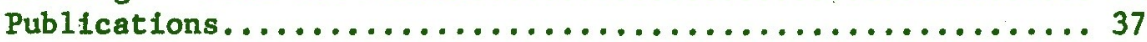

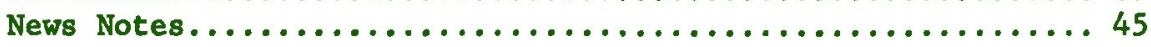

\title{
DENVER MEETING
}

The Fourteenth Annual Meeting of the African Studies Assocfation took place at the Denver Hilton Hotel, November 3-6, and was attended by close to 700 persons. Special thanks go to Professor James B. Wolf (Program Chalrman), Cynthia Kahn (Coordinator), and J. Leo Cefkin (Local Arrangements) whose concern and hard work were in large part responsible for the success of the 1971 meeting which featured fifty panels and workshops. A Denver Post article regarding the Wednesday evening plenary session chaired by Goler T. Butcher, Staff Consultant to the House Subcomittee on Africa, is reprinted in this newsletter on page 45.

A Ilst of papers presented at the Denver meeting and published by the Association is available on request from the Secretarlat (218 Shiffman Center Center, Brandeis University, Waltham, Massachusetts 02154). Panelists who have not already sent a clean copy of their paper to Mary Ann Taylor at this address are requested to do so immediately. 